NBER WORKING PAPER SERIES

\title{
EXCHANGE RATE DYNAMICS WITH SLUGGISH PRICES UNDER ALTERNATIVE PRICE-ADJUSTMENT RULES
}

Maurice Obstfeld

Kenneth Rogoff

Working Paper No. 1173

NATIONAL BUREAU OF ECONOMIC RESEARCH

1050 Massachusetts Avenue

Cambridge MA 02138

August 1983

The research reported here is part of the NBER's research program in International studies. Any opinions expressed are those of the authors and not those of the National Bureau of Economic Research. 
Exchange Rate Dynamics with Sluggish Prices under Alternative PriceAdjustment Rules

\section{ABSTRACT}

This paper studies exchange rate behavior in models with moving longrun equilibria incorporating alternative price-adjustment mechanisms. The paper demonstrates that price-adjustment rules proposed by Mussa and by Barro and Grossman yield models that are empirically indistinguishable from each other. For speeds of goods-market adjustment that are "too fast," the Barro-Grossman rule appears to induce instability; but we argue that when the rule is interpreted properly, models incorporating it are dynamically stable regardless of the speed at which disequilibrium is eliminated. The Barro-Grossman pricing scheme is shown to be a natural generalization, to a setting of moving long-run equilibria, of less versatile schemes proposed in earlier literature on exchange rate dynamics :

Maurice obstfeld Department of Economics International Affairs Building Columbia University New York, NY 10027

(212) 865-9637
Kenneth Rogoff

International Finance Division Board of Governors Federal Reserve System Washington, D.C. 20551

(202) 452-3725 
EXCHANGE RATE DYNAMICS WITH SLUGGISH PRICES UNDER ALTERNATIVE PRICEADJUSTMENT RULES

Maurice Obstfeld and Kenneth Rogof 1 If

\section{INTRODUCTION}

Recent research on the asset-market approach to exchange rates has incorporated short-run Keynesian price rigidities into models assuming rational expectations. These sticky-price models generally exhibit classical properties in the long run, but allow for temporary goods-market disequilibrium in response to real and monetary shocks that are less than perfectly anticipated. A critical element in these models is the pechanism determining how domestic goods prices adjust over time in response both to current disequilibrium and to expectations of future events.

In his seminal paper on exchange-rate determination with sticky domestic prices, Dornbusch [1976] assumed that the nominal price of domestic output is a predetermined variable that moves in response to current goodsmarket disequilibrium only. Mussa [1977, 1982] has criticized the simple Dornbusch adjustment rule as being inadequate in situations where future disturbances are anticipated or where the long-run equilibrium of the economy moves over time. Frankel [1979], Liviatan [1980], and Buiter and Miller [1981, 1982] introduce trend inflation into the Dornbusch model by linking price adjustment to the underlying (constant) money growth rate in addition to direct goods-market pressure. An alternative price-adjustment scheme allowing for very general moving long-run equilibria is derived by Mussa [1981]. The paper compares the price-adjustment rule of Mussa [1981] to a rule advanced by Barro and Grossman [1976] in a closed-economy context. The interest of the Barro-Grossman rule is twofold. First, like Mussa's rule, that of Barro and Grossman is appropriate in models with anticipated future

1/ Columbia University and the Board of Governors of the Federal Reserve System, respectively. This paper represents the views of the author (authors) and should not be interpreted as reflecting the views of the Board of Governors of the Federal Reserve System or other members of its staff. Obstfeld acknowledges with thanks the financial support of the NSF. 
disturbances or nonstationary long-run equilibria. Second, the Barro-Grossiman rule contains the rules of Dornbusch, Frankel, Liviatan, and Buiter and Miller as special cases, and thus has an intuitive interpretation.

The paper's central result is that the Mussa and Barro-Grossman rules, though apparently quite dissimilar, yield structurally equivalent exchange rate models. $-2 /$ Thus, despite the key role of disequilibrium price dynamics, the choice between the two adjustment mechanisms is not necessarily a critical one.

\section{THE LIMITING FLEXIBLE-PRICE MODEL}

The dynamics of a sticky-price exchange rate model with rational expectations can be decomposed into two components. The first component is caused by the system's adjustment to current disequilibrium. The second component is caused by movement of the equilibrium that would obtain if all prices were fully flextble. $\stackrel{3 /}{ }$ Perfectly predictable trend movements in

2/ The models explored below assume that agents have perfect foresight, but the structural equivalence result would carry over to an explicitly stochastic enviroment such as the one assumed by Mussa [1982]. In a stochastic setting, structural equivalence is the same as econometric observational equivalence. The "perfect foresight" assumption allows for the initial arrival of previously unanticipated information concerning the future paths of relevant exogenous varIables. After the initial moment, however, agent' expectationa are fulfilled. 3/ Even if prices are flexible and exogenous variables are stationary, dynamics may arise from the adjustments of nommonetary asset stocks to long-run desired levels, as in Kouri [1976]. The class of models studied in this paper abstracts from the dynamics of asset accumulation. For an analysis of asset accumulation in a sticky-price model, see Henderson [1980]. 
the money supply or in the equilibrlum terms of trade, for example, cause no disequilibrium in a well-specified model, but do induce movements of the system. In this section, we focus on the second source of dynamics by solving a standard exchange rate model under the temporary assumption that domestic prices are fully flexible, or, alternatively, that all movements in the exogenous variables affecting the economy are perfectly anticipated. The equilibrium path of this flexible-price model provides a limiting benchmark for the sticky-price models analyzed later. This benchmark is a natural generalization of the flxed "long-run" equilibrium appearing in sticky-price models whose exogenous variables are static except for onetime unexpected jumps.

The exchange-rate model used here is of the extended small-country variety, and is based on work of Dornbusch [1976] and Mussa [1977, 1982].4/ It is described by the following equations:

$$
m^{d}-\alpha p-(1-\alpha) e=-\lambda r+\psi y \quad \text { (money demand) }
$$

$$
r=r *+\dot{e}
$$

(uncovered interest parity)

$$
y^{d}=\phi(e-p+u)-\sigma[r-\alpha \dot{p}-(1-\alpha) \dot{e}]+\gamma y \quad \text { (aggregate demand) }
$$

(4) $\quad m^{d}=m$ (money-market equilibrium)

(5) $\quad y^{d}=y$ (goods-market equilibrium)

Here, $p$ is the logarithm of the money price of domestically-produced goods; e is the logarithm of the exchange rate (defined as the domestic-currency price of foreign currency); and $r$ is the domestic nominal interest rate. Dots over variables indicate rates of change. $[$ / The remaining variables

4/ See the Dornbusch and Mussa papers for more detailed expositions.

5/ Unless otherwise stated, these rates of change are right-hand derivatives. 
are exogenous: $m$ is the logartithm of the nominal money supply; $\alpha$ is the share of home goods in the domestic consumer price index; $y$ is the logarithm of the flow of perishable home output; $r *$ is the nominal interest rate on foreign-currency bonds; and $u$ is a shock to foreign demand for domestic output. $\alpha$ is assumed to be fixed, and $y$ and $r *$ are assumed to be fixed and equal to zero. The exogenous foreign-currency price of imports is likewise assumed to be constant, with its natural logarithm normalized to zero.

The model assumes rational expectations; this amounts to perfect foresight in the absence of unanticipated shocks. Thus, there is no distinction between actual and anticipated rates of change of $e$ and $p$. Equation (1) is the money-demand schedule, which relates the demand for price-index deflated nominal balances to the home interest rate and income. Equation (2) reflects the assumption that home-currency and foreigncurrency bonds are perfect substitutes. Equation (3) is the aggregatedemand schedule, which posits that demand for domestic output depends on the terms of trade, tastes (as represented by $u$ ), the real rate of interest, and income. Finally equations (4) and (5) require continuous clearing of both the money and goods markets. Condition (5), which entails full flexibility of domestic prices, will be relaxed in subsequent sections. The flex-price equilibrium values of the exchange rate and domestic output price are denoted by $\tilde{e}$ and $\tilde{p}$. Following Sargent and Wallace [1973], we close the model with the assumption that the economy must always lie on its unique conditionally stable saddlepath:-6/ As the appendix shows, the

6/ In models with a well-defined stationary long-run equilibrium, the saddlepath is the unique path converging to long-run equilibrium and thus is the unique path implying nonexplosive behavior for the economy. Saddlepoint stability results from the self-fulfilling nature of rational expectations. 
rational-expectations solution paths for $\tilde{e}$ and $\tilde{p}$ are then given by

$$
\begin{aligned}
\tilde{e}_{t} & =\frac{1}{\lambda} \int_{t}^{\infty} \exp [(t-s) / \lambda] m_{s} d s+\frac{\alpha \omega}{1-\lambda \omega} \int_{t}^{\infty}\{\exp [(t-s) / \lambda]-\exp [\omega(t-s)]\} u_{s} d s \\
\tilde{p}_{t} & =\frac{1}{\lambda} \int_{t}^{\infty} \exp [(t-s) / \lambda] m_{s} d s+\frac{\alpha \omega}{1-\lambda \omega} \int_{t}^{\infty} \exp [(t-s) / \lambda] u_{s} d s \\
& +\frac{\omega[(1-\alpha)-\lambda \omega]}{1-\lambda \omega} \int_{t}^{\infty} \exp [\omega(t-s)] u_{s} d s,
\end{aligned}
$$

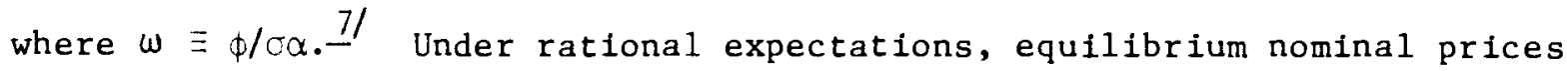
depend on the future expected paths of money and the autonomous component of aggregate demand. Note that monetary factors affect $\tilde{e}_{t}$ and $\tilde{p}_{t}$ by equal amounts, whereas demand shifts affect these variables differentially in general. Thus, while real shocks must be accommodated by shifts in the flex-price real exchange rate $\tilde{q}_{t} \equiv \tilde{e}_{t}-\tilde{p}_{t}, \tilde{q}_{t}$ depends exclusively on factors that shift aggregate demand $y^{d}$, and not on money. In the flex-price model set out here, there is a complete dichotomy between real and monetary phenomena. This classical dichotomy would disappear, for example, if real balances $m_{t}-\alpha p_{t}-(1-\alpha) e_{t}$ were an additional argument in the aggregate demand function. To simplify the analysis, we abstract from real baiance effects.

(FOOTNOTE CONTINUED FROM PREVIOUS PAGE)

Whether there is a stationary long-run equilibrium or a moving long-run equilibrium, the saddlepath can be defined as the unique path of the economy along which prices do not depend in part on pure speculative "bubbles" unrelated to actual market conditions. The appendix discusses the mathematical implementation of this definition in the present context. 7/ These solutions are derived by the method of Laplace transforms. The Laplace transform technique is a convenient one for rational-expectations models, although other solution techniques are available. 


\section{STICKY DOMESTIC PRICES AND ALTERNATIVE PRICE-ADJUSTMENT RULES}

When the price of domestic output is sticky, the goods-market clearing condition (5) need not hold. Following Dornbusch [1976], we assume that the domestic output price is a predetermined or nonjumping variable that adjusts gradually to eliminate goods-market disequilibrium. Dornbusch, who assumes that the exogenous variables are constant except for one-time unanticipated jumps, postulates the following price-adjustment scheme:

$$
\dot{\mathrm{p}}=\pi\left(\mathrm{y}^{\mathrm{d}}-\mathrm{y}\right) \text {. }
$$

While specification (8) is entirely appropriate given the environment Dornbusch assumes, it may become inappropriate once anticipated shocks or trend movements in exogenous variables are introduced. -8 /

Gray and Turnovsky [1979] and Wilson [1979] use the Dornbusch model with adjustment rule (8) to analyze a one-time anticipated increase in the money supply. The solution these authors derive is qualitatively sensible when the disturbance is expected to occur in the near future, but problems arise when (8) is used to study money shocks that are anticipated long before they occur. To see this, consider the economy's behavior as the date of the future money increase recedes infinitely far into the future. As the adjustment period preceding the intended policy act grows longer, the disequilibrium caused by the announcement of that act should disappear. In the limit of a perfectly anticipated money-stock increase -one that is anticipated "Infinitely far" in advance -- the domestic output price and the exchange rate should rise gradually and in proportion toward the long-run equilibrium levels associated with the post-disturbance stock 8/ Mussa [1982] has emphasized these problems. 
of money. $9 /$ However, this equilibrium scenario is impossible with adjustmentrule ( 8 ), because the price level cannot rise in the absence of excess demand. Even perfectly anticipated money shocks must cause goods-market disequilibrium. 10 /

Similar difficulties surround the Franke1 [1979], Liviatan [1980], and Bufter-Miller [1981, 1982] extensions of Dornbusch's price-adjustment

9) Prices naturally exhibit this behavior in the flex-price model of the previous section. When the money shock is expected to occur in finite time and prices are flexible, the domestic output price and exchange rate, after an initial equiproportionate jump when the announcement is made, rise smoothly and in proportion so that the economy is at its long-run equilibrium when the money supply increases. This type of adjustment to imperfectly anticipated shocks is impossible in the sticky-price setting, but it is still true that, after the initial announcement, price evolve smoothly. In particular, the exchange rate cannot jump when the expected money increase takes place, for an anticipated discrete jump would entail an unexploited opportunity to earn an infinite instantaneous rate of return on foreign bonds.

10/ To be precise, the problems with the Gray-Turnovsky and Wilson analyses are not caused exclusively by the price-adjustment scheme these authors adopt. An additional source of nonneutrality is their assumption that aggregate demand is a function of the nominal, rather than the real, domestic interest rate. It is easy to see that in a well-specified model, the nominal interest rate would rise over time during the adjustment to a perfectly anticipated money increase while the real interest rate would remain constant. 
rule to environments of secular inflation. $11 /$ These authors modify (8) by adding to the excess demand term the current rate of nominal money growth. The resulting adjustment rule is

(9) $\quad \dot{\mathrm{p}}=\pi\left(\mathrm{y}^{\mathrm{d}}-\mathrm{y}\right)+\dot{\mathrm{m}}$.

Specification (9) is consistent with an assumption that all changes in the monetary growth rate are unanticipated. But the rule implies unreasonable asymptotic behavior when anticipated changes are analyzed. Consider, for example, a perfectly anticipated increase in the monetary growth rate. With higher trend money growth, long-run m - p is lower. Thus, a perfectly anticipated money-growth increase should cause $m-p$ to decline over time but should not occasion disequilibrium. Because $p$ is predetermined, however, rule (9) implies that $m$ - $p$ can fall over time only if the announcement of the future increase in $\dot{\mathbf{m}}$ creates an excess demand for output that does not vanish as the date of the increase becomes infinitely distant. While the price-adjustment rules described so far are unsatisfactory in many situations, a generalization which contains these rules as special cases is adequate for the analysis of any type of disturbance. Assume now that $\dot{p}$ is a function not only of current disequilibriun, but also of the rate at which the price of domestic output would increase if that price were

11/ Like Dornbusch [1976], section V, Buiter and Miller analyze a model in which output is demand-determined and therefore endogenous. In that model, the disequilibrium term entering their price adjustment rule depends on the difference between actual output and full-employment potential output. Our analysis applies with only minor modifications to variable-output models; see footnote 15 below. 
fully flexible. The resulting price adjustment scheme is

(10) $\quad \dot{\mathrm{p}}=\pi\left(\mathrm{y}^{\mathrm{d}}-\mathrm{y}\right)+\dot{\tilde{\mathrm{p}}}$,

where $\tilde{\mathrm{p}}$ is the flex-price equilibrium output price discussed in the previous section. This type of pricing rule is suggested by Barro and Grossman [1976] in a closed-economy setting, although they do not assume rational expectations regarding $\dot{\tilde{p}} .12 /$ It is easy to see that the Barro-Grossman rule reduces to Dornbusch's rule (8) when the exogenous variables are fixed except for unanticipated jumps, for in that case, $\dot{\tilde{p}}=0$. Similarly, the rule reduces to (9) when the only expected change in the exogenous variables is the growth of money at a constant rate. However, the rule does not redice to Dornbusch's rule (8) in the case of the one-time expected money increase analyzed by Gray and Turnovsky [1979] and by Wilson [1979]. If it is announced at time $t=0$ that the money stock will increase by an amount $\Delta \mathrm{m}$ at time $\mathrm{t}=\mathrm{T}$, then $\dot{\tilde{\mathrm{p}}}_{\mathrm{t}}=(1 / \lambda) \Delta \mathrm{m} \exp [(\mathrm{t}-\mathrm{T}) / \lambda]>0$ for $0 \leq \mathrm{t}<\mathrm{T}$. That the Barro-Grossman rule is immune to the criticisms levelled at rules (8) and (9) is clear. Perfectly anticipated shocks -- whether real or nominal -- do not cause disequilibrium when price adjustment is given by (10). Since the equilibrium flexible-price $\tilde{\mathbf{p}}$ does not jump discontinuously at any point in response to a change announced "infinitely far" in advance, $p$ will fully trace its movements under (10). Mussa [1977, 1982] suggests an alternative rule, and demonstrates that it, too, renders disequilibrium price adjustment unnecessary when shocks are perfectly anticipated. The Mussa rule is given by

(11) $\quad \dot{\mathrm{p}}=\theta\left(\mathrm{y}^{\mathrm{d}}-\mathrm{y}\right)+\dot{\bar{p}}$

12/ See Barro and Grossman [1976, p. 178], equation (4.26). 
where $\bar{p}$ is defined as the domestic output price that would clear the goods market given the actual (possibly disequilibrium) values of the endogenous variables e, $, r, \dot{e}$, and $\dot{p}$. More formally, $\bar{p}_{t}$ is defined by the condition

$$
y=0=\phi\left(e_{t}-\bar{p}_{t}+u_{t}\right)-\sigma\left[r_{t}-\alpha \dot{p}_{t}-(1-\alpha) \dot{e}_{t}\right]
$$

The difference between $\bar{p}$ and $\tilde{p}$ deserves emphasis. $\tilde{p}$ is the output pirice that would prevall in a hypothetical Walrasian general equilibrium with fully flexible prices. $\bar{p}$ is the output price that would clear the goods market given current levels of the sticky-price system's endogenous variables. Alternative microeconomic rationales for the Mussa price-adjustment rule are presented in McCallum [1980], Mussa [1981], and Flood [1982b]. Mussa's derivation, for example, assumes monopolistic firms for whom price changes are costly. Flood's inventory-adjustment story assumes that firms set their prices a period in advance of market transactions. $13 /$

The Barro-Grossman rule (10) and the Mussa rule (11) appear quite unrelated, and it is natural to ask how these different price-adjustment schemes affect the dynamic behavior of the economy. We address this question In. the next section by comparing explicit solutions of models incorporating the two rules.

13/ Flood's justification of the Mussa rule is based on work of Green and Laffont [1981]. Rotemberg [1981] points out some limitations of Mussa's [1981] rationale. 
4. THE STRUCTURAL EQUIVALENCE OF THE BARRO-GROSSMAN AND MUSSA PR ICE-ADJUSTMENT RULES

The following result clarifies the relationship between the BarroGrossman and Mussa pricing rules:

THEOREM. Provided that the condition

$$
1-\pi \alpha \sigma>0
$$

is satisfied, the Barro-Grossman price adjustment scheme (10) and the Mussa price adjustment scheme (11) yield structurally equivalent exchange rate models.

PROOF. The appendix demonstrates [see equations (A18) and (A19)] that when (13) holds, the rational-expectations equilibrium of the model described by equations (1) through (4) and the Barro-Grossman rule (10) is given by

$$
\begin{aligned}
& \text { (14a) } e_{t}^{B G}=\frac{-\left(p_{0}-\tilde{p}_{0}\right) \alpha}{\left[(1-\alpha)-\lambda \eta_{2}\right]} \exp \left(\eta_{2} t\right)+\tilde{e}_{t} \\
& \text { (14b) } p_{t}^{B G}=\left(p_{0}-\tilde{p}_{0}\right) \exp \left(\eta_{2} t\right)+\tilde{p}_{t},
\end{aligned}
$$

where

$$
\eta_{2}=\frac{-[\lambda \pi \phi+\pi \alpha \sigma-(1-\alpha)]}{2 \lambda(1-\pi \alpha \sigma)}-\left\{\frac{[\lambda \pi \phi+\pi \alpha \sigma-(1-\alpha)]^{2}}{4 \lambda^{2}(1-\pi \alpha \sigma)^{2}}+\frac{\pi \phi}{(1-\pi \alpha \sigma)}\right\}^{\frac{1}{2}}<0
$$
and $\tilde{\mathrm{e}}_{t}$ and $\tilde{\mathrm{p}}_{t}$ again denote the equilibrium solutions for the flex-price model of section 2. When the Mussa rule (11) is substituted for (10), the rationalexpectations equilibrium is given by

(16a) $\quad e_{t}^{M}=\frac{-\left(p_{0}-\tilde{p}_{0}\right) \alpha}{[(1-\alpha)+\lambda \theta \phi]} \exp (-\theta \phi t)+\tilde{e}_{t}$

$$
p_{t}^{M}=\left(p_{0}-\tilde{p}_{0}\right) \exp (-9 \phi t)+\tilde{p}_{t}
$$


[see the appendix, equacions (A35) and (A36)]. The two sets of solutions can be made numerically equal by choosing $\theta$ (the speed-of-adjustment parameter in the Mussa model) so that

$$
\text { (17) } \theta=\frac{[\lambda \pi \phi+\pi \alpha \sigma-(1-\alpha)]}{2 \phi \lambda(1-\pi \alpha \sigma)}+\left\{\frac{[\lambda \pi \phi+\pi \alpha \sigma-(1-\alpha)]^{2}}{4(\phi \lambda)^{2}(1-\pi \alpha \sigma)^{2}}+\frac{\pi}{\phi \lambda(1-\pi \alpha \sigma)}\right\}^{\frac{1}{2}} \text {, }
$$

for when $\theta$ is so chosen, $-\theta \phi=\eta_{2}[$ cf. (15)]. The two models are therefore structurally equivalent.

It is important to note that the theorem holds only along the saddlepath. The models are not structurally equivalent elsewhere.

When condition (13) is violated (as it necessarily is for $\pi$ sufficiently large), the model with the Barro-Grossman adjustment rule has two characteristic roots with positive real part. Sadilepath stability requires that a negative root be associated with each predetermined variable in the model; and because $p$ is predetermined, a rational-expectations equilibrium will not exist in general when (13) fails and the model is unstable.․/ In contrast, the Mussa rule necessarily yields saddlepath stability for any nonnegative values of the system's parameters; and as the speed-of-adjustment parameter $\theta \rightarrow+\infty$, the Mussa model converges smoothly to the flex-price model. It seems worrisome, at first glance, that under the Barro-Grossman rule, the economy becomes unstable and does not converge to the flex-price model as $\pi \rightarrow+\infty$. We will argue shortly that when the price adjustment implied by the Barro-Grossman mechanism is interpreted properly, (13) always holds and this apparent convergence problem disappears.

14 The instability is due to the fact that when (13) does not hold, a positive shock to aggregate demand (an increase in u) leads, ceteris paribus, to falling prices. 
The following result makes apparent the essential reason for the two models' structural equivalence:

COROLLARY. Along the saddlepath of the Mussa model, the output price $p$ obeys a differential equation having the same form as the Barro-Grossman equation (10). More precisely, along the saddlepath of the Mussa model,

$$
\dot{\mathrm{p}}^{\mathrm{M}}=\delta\left(\mathrm{y}^{\mathrm{d}}-\mathrm{y}\right)+\dot{\tilde{\mathrm{p}}}
$$

where

(19) $\delta=\frac{\theta[(1-\alpha)+\lambda \theta \phi]}{(1+\theta \alpha \sigma)(1+\lambda \theta \phi)}$.

PROOF. Letting $q_{t}$ once again denote the real exchange rate $e_{t}-p_{t}$, we may use (3) to write excess demand in the Mussa model as

$$
\text { (20) } \quad y_{t}^{d}-y=\phi\left(q_{t}^{M}-\tilde{q}_{t}\right)-\alpha \sigma\left(\dot{q}_{t}^{M}-\dot{\tilde{q}}_{t}\right)
$$

Equation (A28) of the appendix implies that on the saddlepath of the Mussa mode1,

$$
\dot{q}_{t}^{M}-\dot{\tilde{q}}_{t}=-\theta \phi\left(q_{t}^{M}-\tilde{q}_{t}\right)
$$

Equations (20) and (21) together imply that

$$
y_{t}^{d}-y=\cdot \phi(1+\theta \alpha \sigma)\left(q_{t}^{M}-\tilde{q}_{t}\right)=\phi(1+\theta \alpha \sigma)\left[\left(e_{t}^{M}-\tilde{e}_{t}\right)-\left(p_{t}^{M}-\tilde{p}_{t}\right)\right]
$$

Using equations (16a) and (16b), we have

$$
e_{t}^{M}-\tilde{e}_{t}=\frac{-\alpha\left(p_{t}^{M}-\tilde{p}_{t}\right)}{[(1-\alpha)+\lambda \theta \phi]} \text {. }
$$

Combining (22) and (23) yields

$$
p_{t}^{M}-\tilde{p}_{t}=\frac{-[(1-\alpha)+\lambda \theta \phi]}{\phi(1+\theta \alpha \sigma)(1+\lambda \theta \phi)}\left(y_{t}^{d}-y\right)
$$

Because, by $(16 \mathrm{~b}), \dot{\mathrm{p}}_{t}^{\mathrm{M}}=-\theta \phi\left(\mathrm{p}_{t}^{\mathrm{M}}-\tilde{\mathrm{p}}_{t}\right)+\dot{\tilde{p}}_{t}$ along the Mussa model's saddlepath, (24) implies that 


$$
\dot{\mathrm{p}}_{t}^{\mathrm{M}}=\frac{\theta[(1-\alpha)+\lambda \theta \phi]}{(1+\theta \alpha \sigma)(1+\lambda \theta \phi)}\left(y_{t}^{\mathrm{d}}-\mathrm{y}\right)+\dot{\tilde{\mathrm{p}}}_{\mathrm{t}}
$$

The foregoing corollary shows why the Mussa model is necessarily saddlepath stable. Although prices in that model do adjust according tc a Barro-Grossman-type rule, the model can never be unstable because, by (19), the stability criterion

$$
1-\delta \alpha \sigma>0
$$

is always satisfied [cf. equation (13)]. By assuming the Mussa rule, we effectively limit the parameter $\delta$ to values between $0(\theta=0)$ and $1 / \alpha \sigma(\theta=+\infty)$. Even though the Mussa rule places an upper bound on the excess-demand coefficient $\delta$ appearing in (18), there is no upper bound on the speed at which goodsmarket disequilibrium is eliminated. As was pointed out above, the Mussa model converges to the equilibrium flex-price model as $\theta \rightarrow+\infty$ and $\delta \rightarrow 1 / \alpha \sigma$.

A consequence of these findings is that the speed of goods-market adjustment under the Barro-Grossman rule (10) becomes infinite as $\pi \rightarrow 1 / \alpha \sigma$. Accordingly, that rule yields a saddlepoint-stable model for any speed of goods-market adjustment. Contrary to appearances, the stability condition (13) does not limit one to adjustment speeds which are not too great.

15/ The isomorphism results presented here are readily extended to variable-output versions of the exchange rate model, like that of Buiter and Miller [1981, 1982 ] and those compared by Flood [1982a ]. The stability condition when the Barro-Grossman mechanism is used is slightly more complicated in the variable-output case if money demand depends on actual output. The stability criterion, in that case, is $\lambda(1-\gamma)+\alpha \sigma \psi-\lambda \pi \alpha \sigma>0$. Otherwise, the isomorphism between variable-output models incorporating the Barro-Grossman rule and those incorporating the Mussa rule can be proved as in the text. 
5. CONCLUSION

This paper has studied the consequences of adopting alternative sticky-price adjustment rules in exchange rate models characterized by moving long-run equilibria. A price-adjustment scheme suggested by Barro and Grossman [1976] in a different context was shown to be a natural generalization of less versatile price-adjustment schemes advanced by Dornbusch [1976], by Franke1 [1979], by Liviatan [1980], and by Buiter and Miller [1981, 1982 ]. It was also demonstrated that use of the Barro-Grossman rule results in an exchange rate model that is structurally equivalent to one based on the apparently quite different price-adjustment rule proposed by Mussa [1977, 1982]. The choice between the Barro-Grossman and Mussa rules is therefore not critical for many theoretical and empirical applications. $\frac{16 /}{\text { Unlike the }}$ simpler price-adjustment rules used in earlier studies, either yields sensible results for any expected path of the exogenous variables driving the system.

16/ As Lucas [1976] argues, changes of policy regime could alter the parameters appearing in the two rules. In some cases it may be easier to model this possibility using the Mussa rule, which at present has a somewhat better-developed microeconomic rationale. 


\section{APPENDIX}

This appendix calculates explicit solution paths for the flexible-price exchange rate model and the two sticky-price models discussed in the text. These rational-expectations models are solved by the method of Laplace transforms, which is equivalent to the operator solution procedure described by Sargent [1979]. 1/ The Laplace transform of a function $\mathrm{F}_{t}$ is defined by

$$
L\left(f_{t}\right)=\int_{0}^{\infty} \exp (-\ell t) f_{t} d t
$$

and is a function of $\ell .2 /$ The key theorem invoked below is that a continuous function is uniquely determined on $(0, \infty)$ by its Laplace transform (see Sokolnikoff and Redheffer [1966]). It is easy to verify that: (i) $\mathrm{L}(\cdot)$ is linear; (ii) $\mathrm{L}\left(\dot{\mathrm{f}}_{\mathrm{t}}\right)=\ell \mathrm{L}\left(\mathrm{f}_{\mathrm{t}}\right)-\mathrm{f}_{0}$; (iii) $\mathrm{L}\left(\mathrm{f}_{\mathrm{t}}\right) \mathrm{L}\left(\mathrm{g}_{\mathrm{t}}\right)=\mathrm{L}\left(\int_{0}^{\mathrm{t}} \mathrm{f}_{\mathrm{s}} \mathrm{g}_{\mathrm{t}-\mathrm{s}} \mathrm{ds}\right)$. These three properties will be used repeatedly in what follows.

\section{The Flex-Price Mode1}

The flex-price model may be written in the form

(A2)

$$
\dot{e}_{t}=[(1-\alpha) / \lambda] e_{t}+(\alpha / \lambda) p_{t}-m_{t} / \lambda
$$

$$
\dot{p}_{t}=-w e_{t}+w p_{t}+\dot{e}_{t}-w u_{t}
$$

where $\omega \equiv \phi / \sigma \alpha$. The Laplace transform of the system given by (A2) and (A3) may be written in matrix notation as

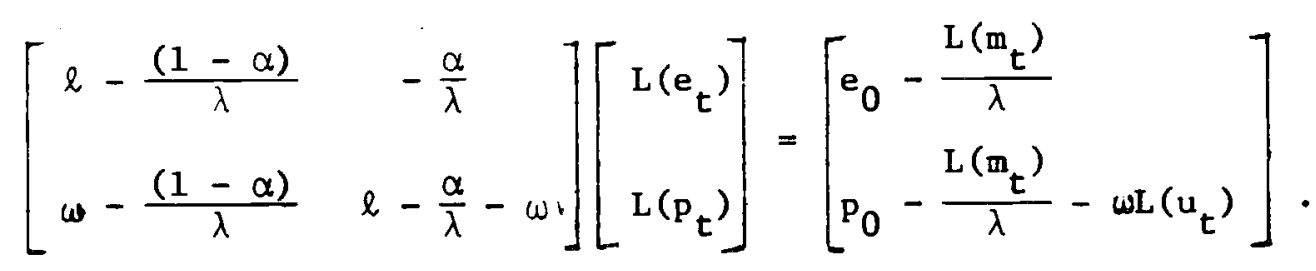

1/ The advantages of the Laplace transform method are that it 18 completely algorithmic and that it produces solutions which are expressed in terms of the state variables' initial positions.

2/ The transform is defined only for $\ell$ such that the integral in (Al) converges. 
By solving these simultaneous equations we obtain

$$
\begin{aligned}
& L\left(e_{t}\right)=\frac{[\lambda(l-\omega)-\alpha] e_{0}+\alpha p_{0}+(\omega-\ell) L\left(m_{t}\right)-\alpha \omega L\left(u_{t}\right)}{\lambda[\ell-(1 / \lambda)][\ell-\omega]}, \\
& L\left(p_{t}\right)=\frac{[(1-\alpha)-\lambda \omega] e_{0}+[\lambda \ell-(1-\alpha)] p_{0}+(\omega-\ell) L\left(m_{t}\right)+\omega[(1-\alpha)-\lambda \ell] L\left(u_{t}\right)}{\lambda[\ell-(1 / \lambda)][\ell-\omega]} .
\end{aligned}
$$

A partial-fraction expansion of (A4) leads to the representation

$$
\begin{aligned}
L\left(e_{t}\right) & =\frac{\alpha p_{0}-(\alpha+\lambda \omega) e_{0}}{\lambda[(1 / \lambda)-\omega]}\left[\frac{1}{\ell-(1 / \lambda)}-\frac{1}{\ell-\omega}\right] \\
& +\frac{\lambda e_{0}}{\lambda[(1 / \lambda)-\omega]}\left[\frac{(1 / \lambda)}{\ell-(1 / \lambda)}-\frac{\omega}{\ell-\omega}\right] \\
& +\frac{\omega}{\lambda[(1 / \lambda)-\omega]} L\left(\int_{0}^{t}\{\exp [(t-s) / \lambda]-\exp [\omega(t-s)]\} m_{s} d s\right) \\
& -\frac{1}{\lambda[(1 / \lambda)-\omega]} L\left(\int_{0}^{t}\left\{(1 / \lambda) \exp [(t-s / \lambda]-\omega \exp [\omega(t-s)]\} m_{s} d s\right)\right. \\
& -\frac{\alpha \omega}{\lambda[(1 / \lambda)-\omega]} L\left(\int_{0}^{t}\{\exp [(t-s) / \lambda]-\exp [\omega(t-s)]\} u_{s} d s\right) .
\end{aligned}
$$

In deriving (A6), we have used the convolution property (1ii) and the facts that $L[\exp (t / \lambda)]=[\ell-(1 / \lambda)]^{-1}, L[\exp (\omega t)]=(\ell-\omega)^{-1}$.

The Laplace transform theorem allows us to infer from (A6) that the exchange rate path has the form

$$
\begin{aligned}
e_{t} & =\frac{(1-\lambda \omega-\alpha) e_{0}+\alpha p_{0}}{1-\lambda \omega} \exp (t / \lambda)+\frac{\alpha\left(e_{0}-p_{0}\right)}{1-\lambda \omega} \exp (\omega t) \\
& \left.-\frac{1}{\lambda} \int_{0}^{t} \exp [(t-s) / \lambda] \mathrm{m}_{s} d s-\frac{\alpha \omega}{1-\lambda \omega}\right\}_{0}^{t}[\exp [(t-s) / \lambda]-\exp [\omega(t-s)]\}_{s} d s .
\end{aligned}
$$

It is convenient to rewrite $(A i)$ in the equivalent form 
(A8) $\quad e_{t}=\frac{\left\{(1-\lambda \omega-\alpha) e_{0}+\alpha p_{0}-[(1 / \lambda)-\omega] \int_{0}^{\infty} \exp (-s / \lambda) m_{s} d s-\alpha \omega \int_{0}^{\infty} \exp (-s / \lambda) u_{s} d s\right\}}{1-\lambda \omega} \exp (t / \lambda)$

$$
\begin{aligned}
& +\frac{\left[\alpha\left(e_{0}-p_{0}\right)+\alpha \omega \int_{0}^{\infty} \exp (-\omega s) u_{s} d s\right]}{1-\lambda \omega} \exp (\omega t) \\
& +\frac{1}{\lambda} \int_{t}^{\infty} \exp [(t-s) / \lambda] m_{s} d s+\frac{\alpha \omega}{1-\lambda \omega} \int_{t}^{\infty}\{\exp [(t-s) / \lambda]-\exp [\omega(t-s)]\} u_{s} d s .
\end{aligned}
$$

Equation (A8) expresses the path of the exchange rate as a function of its own initial value $\left(e_{0}\right)$ and the initial value of the price of domestic output $\left(\mathrm{p}_{0}\right)$. These two initial conditions are uniquely determined by the saddlepath assumption, which requires that the coefficients of the explosive "bubble" terms, $\exp (t / \lambda)$ and $\exp (\omega t)$, be zero (see Sargent and Wallace [1973]). The requirement that the economy be on its saddlepath implies [by (A8)] that

$$
\tilde{\mathbf{e}}_{0}=\frac{1}{\lambda} \int_{0}^{\infty} \exp (-s / \lambda) \mathrm{m}_{s} \mathrm{ds}+\frac{\alpha \omega}{1-\lambda \omega} \int_{0}^{\infty}\{\exp (-s / \lambda)-\exp (-\omega s)\} u_{s} d s,
$$

$$
+\frac{\omega[(1-\alpha)-\lambda \omega]}{1-\lambda_{0}} \int_{0}^{\infty} \exp \left(-\mu_{s}\right) u_{s} d s
$$

where a tilde denotes a saddlepath equilibrium value for the flex-price model. Combining (A8), (A9), and (A10), we obtain the rational-expectations equilibrium value of the exchange rate

$$
\tilde{e}_{t}=\frac{1}{\lambda} \int_{t}^{\infty} \exp [(t-s) / \lambda] m_{s} d s+\frac{\alpha \omega}{1-\lambda \omega} \int_{t}^{\infty}\left\{\exp [(t-s) / \lambda]-\exp [\omega(t-s]\}_{s} d s .\right.
$$

A derivation similar to the foregoing shows that the flex-price equilibrium domestic output price can be written as 
(A12)

$$
\begin{aligned}
\tilde{p}_{t} & =\frac{1}{\lambda} \int_{t}^{\infty} \exp [(t-s) / \lambda] \mathbf{m}_{s} d s+\frac{\alpha \omega}{1-\lambda \omega} \int_{t}^{\infty} \exp [(t-s) / \lambda] u_{s} d s \\
& +\frac{\omega[(1-\alpha)-\lambda \omega]}{1-\lambda \omega} \int_{t}^{\infty} \exp [\omega(t-s)] u_{s} d s .
\end{aligned}
$$

According to (Al1) and (A12), the flex-price exchange rate and domestic output price depend both on future expected monetary disturbances (represented by $m_{s}$ ) and future expected real disturbances (represented by $\left.u_{s}\right)$. However the $f$ lex-price real exchange rate $\tilde{q}_{t}$, defined as $\tilde{e}_{t}-\tilde{p}_{t}$, is given by

(A13) $\quad \tilde{q}_{t}=-\omega \int_{t}^{\infty} \exp [\omega(t-s)] u_{s} d s$.

The real exchange rate thus depends exclusively on current and anticipated future real shocks; it is not influenced by monetary factors. Expression (A13) reflects the real-monetary dichotomy that characterizes the flex-price exchange-rate model.

2. St1cky Prices and the Barro-Grossman Adjustment Rule

To introduce sticky prices and the Barro-Grossman adjustment scheme, assume that the domestic ouput price is a predetermined variable and replace the goods-market equilibrium condition (A3) with the equation

$$
\dot{\mathrm{p}}_{t}=\pi\left[\phi\left(e_{t}-p_{t}+u_{t}\right)-\alpha \sigma\left(\dot{e}_{t}-\dot{p}_{t}\right)\right]+\dot{\tilde{p}}_{t}
$$

where $\tilde{p}_{t}$ again represents the flex-price equilibrium output price derived in the previous section. Equilibrium $e_{t}$ and $p_{t}$ in the present model satisfy (A2) and (A14), while $\tilde{e}_{t}$ and $\tilde{p}_{t}$ satisfy (A2) and (A3). It follows that under the Barro-Grossman price dynamics, the exchange rate and output 
price obey the equations

$$
\dot{e}_{t}^{\prime}=[(1-\alpha) / \lambda] e_{t}^{\prime}+(\alpha / \lambda) p_{t}^{\prime}
$$

$$
\dot{p}_{t}^{\prime}=\pi\left[\phi\left(e_{t}^{\prime}-p_{t}^{\prime}\right)-\alpha \sigma\left(\dot{e}_{t}^{\prime}-\dot{p}_{t}^{\prime}\right)\right]
$$

where $e_{t}^{\prime} \equiv e_{t}-\tilde{e}_{t}$ and $p_{t}^{\prime} \equiv p_{t}-\tilde{p}_{t} \cdot$ Equations (A15) and (A16), when combined, yield

(A17) $\quad \dot{\mathrm{p}}_{\mathrm{t}}^{\prime}=\frac{[\lambda \pi \phi-\alpha(1-\alpha) \pi \sigma]}{\lambda(1-\pi \alpha \sigma)} \mathrm{e}_{\mathrm{t}}^{\prime}-\frac{\left(\lambda \pi \phi+\alpha^{2} \pi \sigma\right)}{\lambda(1-\pi \alpha \sigma)} \mathrm{p}_{\mathrm{t}}^{\prime}$.

Together (A15) and (Al7) describe an autonomous differential equation system in $e_{t}^{\prime}$ and $p_{t}^{\prime}$.

The characteristic roots of that system, $\eta_{1}$ and $n_{2}$, are given by

$$
n_{1}, \eta_{2}=\frac{-[\lambda \pi \phi+\pi \alpha \sigma-(1-\alpha)]}{2 \lambda(1-\pi \alpha \sigma)} \pm\left\{\frac{[\lambda \pi \phi+\pi \alpha \sigma-(1-\alpha)]^{2}}{4 \lambda^{2}(1-\pi \alpha \sigma)^{2}}+\frac{\pi \phi}{(1-\pi \alpha \sigma)}\right]^{\frac{1}{2}}
$$

Provided that the condition $1-\pi \alpha \sigma>0$ is met, $\eta_{1}>0$ and $\eta_{2}<0$, as required for saddlepath stability when one of the two endogenous variables is predetermined. By imposing the requirement that the economy be on the stable saddlepath, we obtain the rational-expectations solution

(A18) $\quad e_{t}=\frac{-\left(p_{0}-\tilde{p}_{0}\right) \alpha}{\left[(1-\alpha)-\lambda \eta_{2}\right]} \exp \left(\eta_{2} t\right)+\tilde{e}_{t}$,

(A19) $\quad p_{t}=\left(p_{0}-\tilde{p}_{0}\right) \exp \left(\eta_{2} t\right)+\tilde{p}_{t}$

According to (A18) and (A19), $e_{t}$ and $p_{t}$ converge to their flex-price values $\tilde{e}_{t}$ and $\tilde{p}_{t}$ at a rate given by $\left|\eta_{2}\right|$. At any point, the deviation of actual $e_{t}$ or $p_{t}$ from its flex-price value is proportional to the initial discrepancy between the predetermined initial output price $\mathrm{P}_{0}$ and its flex-price level $\tilde{\mathrm{p}}_{0}$ given by (A10). If there is no disequilibrium initially, 
a divergence between $\mathrm{p}_{0}$ and $\tilde{\mathrm{p}}_{0}$ can arise only as the result of previously unanticipated information arriving at time $t=0$.

3. Sticky Prices and the Mussa Adjustment Rule

The Mussa model results from replacing (A14) by the price-adjustment rule

(A20) $\dot{\mathrm{p}}_{t}=\theta\left[\phi\left(\mathrm{e}_{\mathrm{t}}-\mathrm{p}_{t}+\mathrm{u}_{t}\right)-\alpha \sigma\left(\dot{\mathrm{e}}_{t}-\dot{\mathrm{p}}_{t}\right)\right]+\dot{\bar{p}}_{t}$, where $\bar{p}_{t}$ is defined by the condition

$$
\phi\left(e_{t}-\bar{p}_{t}+u_{t}\right)-\alpha \sigma\left(\dot{e}_{t}-\dot{p}_{t}\right)=0
$$

If we differentiate (A21) and substitute the result into (A20), we obtain

$$
\dot{p}_{t}=\theta\left[\phi\left(e_{t}-p_{t}+u_{t}\right)-\alpha \sigma\left(\dot{e}_{t}-\dot{p}_{t}\right)\right]+\dot{e}_{t}+\dot{u}_{t}-(1 / \omega)\left(\ddot{e}_{t}-\ddot{p}_{t}\right)
$$

(recall that $\omega \equiv \phi / \sigma \alpha)$. Using the definition of the real exchange rate, $q_{t} \equiv e_{t}-p_{t}$, we may rewrite (A22) as a single, second-order differential equation in $q_{t}$,

$$
\ddot{a}_{t}-\omega(1-\theta \alpha \sigma) \dot{q}_{t}-\omega \theta q_{\hat{t}}=\omega \theta \phi u_{\hat{t}}+\omega \dot{u}_{t} .
$$

Even though the level of $q_{t}$ depends on the initial sticky nominal price of domestic goods, the adjustment law for $q_{t}$ involves real factors only.

The model consisting of (A2) and (A22) will be solved in three steps. First, (A23) will be solved to obtain the rational-expectations path of the real exchange rate $q_{t}$. Second, equation (A2), rewritten as

$$
\dot{e}_{t}=(1 / \lambda) e_{t}-(\alpha / \lambda) q_{t}-m_{t} / \lambda
$$

will be used in conjunction with the solution for $q_{t}$ to obtain the path of $e_{t}$ and the initial values $e_{0}$ and $q_{0}$. Third, the identity $p_{t} \equiv e_{t}-q_{t}$ will be used to derive the path of the domestic output price. 
The Laplace transform, applied to (A23), yields the equation

$$
L\left(q_{t}\right)=\frac{\dot{q}_{0}+(l-\omega+\theta \phi) q_{0}+\omega(\theta \phi+l) L\left(u_{t}\right)}{(l+\theta \phi)(l-\omega)} .
$$

Equation (A25) is based on the normalization $u_{0}=0$. After partialfraction expansion, (A25) becomes

$$
L\left(q_{t}\right)=-\left(\frac{\dot{q}_{0}-\omega q_{0}}{\omega+\theta \phi}\right)\left[\frac{1}{\ell+\theta \phi}\right]+\left[\left(\frac{\dot{q}_{0}+\theta \phi q_{0}}{\omega+\theta \phi}\right)+\omega L\left(u_{t}\right)\right]\left[\frac{1}{\ell-\omega}\right] .
$$

The Laplace transform theorem now implies that

$$
\begin{aligned}
q_{t} & =-\left(\frac{\dot{q}_{0}-\omega q_{0}}{\omega+\theta \phi}\right) \exp (-\theta \phi t)+\left(\frac{\dot{q}_{0}+\theta \phi q_{0}}{\omega+\theta \phi}\right) \exp (\omega t)+\omega \int_{0}^{t} \exp [\omega(t-s)] u_{s} d s \\
& =-\left(\frac{\dot{q}_{0}-\omega q_{0}}{\omega+\theta \phi}\right) \exp (-\theta \phi t)+\left[\left(\frac{\dot{q}_{0}+\theta \phi q_{0}}{\omega+\theta \phi}\right)+\omega \int_{0}^{\infty} \exp (-\omega s) u_{s} d s\right] \exp (\omega t) \\
& -\int_{t}^{\infty} \exp [\omega(t-s)] u_{s} d s .
\end{aligned}
$$

The saddlepath assumption requires that the coefficlent of $\exp (\omega t)$ in (A26) be zero. Thus, $\dot{q}_{0}$ and $q_{0}$ must satisfy the relation

$$
\dot{q}_{0}-\omega q_{0}=-(w+\theta \phi)\left[q_{0}+w \int_{0}^{\infty} \exp (-\omega s) u_{s} d s\right]
$$

Combining (A13), (A26), and (A27), we find that

$$
q_{t}=\left(q_{0}-\tilde{q}_{0}\right) \exp (-\theta \phi t)+\tilde{q}_{t}
$$

The effect of Mussa's price-adjustment mechanism is to drive the real exchange rate toward its flex-price level at a rate given by $\theta \phi$.

To solve for $e_{t}$, we write (A24) in terms of deviations from flex-price equilibrium values, 
(A29)

$$
\dot{e}_{t}^{\prime}=(1 / \lambda) e_{t}^{\prime}-(\alpha / \lambda) q_{t}^{\prime}
$$

where $e_{t}^{\prime} \equiv e_{t}-\tilde{e}_{t}$ as before and $q_{t}^{\prime} \equiv q_{t}-\tilde{q}_{i}$. Differentiation of (A28) gives

(A30) $\quad \dot{q}_{t}^{\prime}=-\theta \phi q_{t}^{\prime}$.

The characteristic roots of the autonomous system described by (A29) and (A30) are clearly $1 / \lambda$ and $-\theta \phi$. Imposition of the saddlepath assumption leads to the exchange rate solution

(A31) $\quad e_{t}=\frac{\left(q_{0}-\tilde{q}_{0}\right) \alpha}{(1+\lambda \theta \phi)} \exp (-\theta \phi t)+\tilde{e}_{t}$

The initial values $e_{0}$ and $q_{0}$ may be recovered from (A31), given $p_{0}$. Substituting $e_{0}-p_{0}$ for $q_{0}$ and setting $t=0$ gives

(A32) $\quad e_{0}=\frac{-\left(\mathrm{p}_{0}-\tilde{\mathrm{p}}_{0}\right) \alpha}{[(1-\alpha)+\lambda \theta \phi]}+\tilde{\mathrm{e}}_{0}$,

(A33) $q_{0}=\frac{-\left(p_{0}-\tilde{p}_{0}\right)(1+\lambda \theta \phi)}{[(1-\alpha)+\lambda \theta \phi]}+\tilde{q}_{0}$.

Thus, (A28) may be written as

(A34) $q_{t}=\frac{-\left(p_{0}-\tilde{p}_{0}\right)(1+\lambda \theta \phi)}{[(1-\alpha)+\lambda \theta \phi]} \exp (-\theta \phi t)+\tilde{q}_{t}$,

while (A3I) takes the form

(A35) $\quad e_{t}=\frac{-\left(p_{0}-\tilde{p}_{0}\right) \alpha}{[(1-\alpha)+\lambda \theta \phi]} \exp (-\theta \phi t)+\tilde{e}_{t}$. 
The path of the domestic output price $p_{t}$ is readily derived from (A34) and (A35). It is given by

(A36) $\quad p_{t}=\left(p_{0}-\tilde{p}_{0}\right) \exp (-\theta \phi t)+\tilde{p}_{t}$.

In the wake of an unanticipated disturbance, the sticky price of domestic goods converges to its flex-price value at a rate given by $\theta \phi$. 


\section{REFERENCES}

Barro, R.J. and H.I. Grossman, Money, Employment and Inflation, (London: Cambridge University Press, 1976).

Buiter, W.H. and M.H. Miller, "Monetary Policy and International Competitiveness: The Problems of Adjustment," Oxford Economic Papers 33 (July, 1981), 143-175.

, "Real Exchange Rate Overshooting and the Output Cost of Bringing Down Inflation," European Economic Review 18 (May/June, 1982), 85-123.

Dornbusch, R., "Expectations and Exchange Rate Dynamics," Journal of Political Economy 84 (December, 1976), 1161-1176.

Flood, R., "Comment on the Buiter and Miller Paper," European Economic Review 18 (May /June, 1982a), 125-127. , "Sticky Prices and Inventory Adjustment," Board of Governors of the Federal Reserve System, mimeo (February,1982b).

Franke1, J. A., "On the Mark: A Theory of Floating Exchange Rates Based on Real Interest Differentials," American Economic Review 69 (September,1979), 610-622.

Gray, M. R. and S. J. Turnovsky, "The Stability of Exchange Rate Dynamics under Myopic Perfect Foresight," International Economic Review 20 (Ocotober,1979), 643-660.

Green, J. and J. J. Laffont, "Disequilibrium Dynamics with Inventories and Anticipatory Price-Setting," European Economic Review 16 (May,1981), 199-221. 
Henderson, D. W., "The Dynamic Effects of Exchange Market Intervention Policy: Two Extreme Views and a Synthesis," in H. Frisch and G. Schwödiauer, eds., The Economics of Flexible Exchange Rates, supplement to Kredit und Kapital 6 (Ber11n: Duncker and Humblot, 1980).

Kouri, P. J. K., "The Exchange Rate and the Balance of Payments in the Short Run and in the Long Run: A Monetary Approach," Scandinavian Journal of Economics 2 (May, 1976), 280-304.

Liviatan, N., "Anti-inflationary Monetary Policy and the Capital Import Tax," Warwick Economic Research Paper, No. 171, University of Warwick, 1980.

Lucas, R. E. Jr., "Econometric Policy Evaluation: A Critique," in

K. Brunner and A. H. Meltzer, eds., The Phillips Curve and Labor Markets (Amsterdam: North Holland, 1976).

McCallum, B. T., "Rational Expectations and Macroeconomic Stabilization Policy: An Overview," Journal of Money, Credit, and Banking 12 (November, 1980), 716-746.

Mussa, M., "A Dynamic Theory of Foreign Exchange," in M. Artis and A. Nobay, eds., Studies in Modern Economic Analysis: The Proceedings of the Association of University Teachers of Economics (Oxford: Basil Blackwe11, 1977).

, "Sticky Prices and Disequilibrium Adjustment in a Rational

Model of the Inflationary Process," American Economic Review 71

(December, 1981), 1020- 1027 . 
Mussa, M., "A Model of Exchange Rate Dynamics," Journal of Political Economy 90 (February, 1982), 74-104.

Rotemberg, J. J., "Fixed Costs of Price Adjustment and the Cost of Inflation," Sloan School of Management, M.I.T., mimeo (December,1981).

Sargent, T.J., Macroeconomlc Theory, (New York: Academic Press, 1979).

Sargent, T.J. and N. Wallace, "The Stability of Models of Money and Perfect Foresight," Econometrica 41 (November, 1973), 1043-1048.

Sokolnikoff, I. S. and R. M. Redheffer, Mathematics of Physics and Modern Engineering, 2nd edition, (New York: McGraw-Hi11, 1966).

Wilson, C., "Anticipated Shocks and Exchange Rate Dynamics," Journal of Political Economy 87 (June, 1979), 639-647. 